\title{
Tattoos in Psychodermatology
}

\author{
İlknur Kıvanç Altunay ${ }^{1}$, Sibel Mercan ${ }^{2}$ and Ezgi Özkur ${ }^{1, *}$ \\ 1 Department of Dermatology, University of Health Sciences, Şişli Etfal Training and Research Hospital, \\ Istanbul 34371, Turkey; ialtunay@gmail.com \\ 2 Department of Psychiatry, Istanbul Gedik University, Istanbul 34876, Turkey; sibelmercan@yahoo.com \\ * Correspondence: ezgierdal@hotmail.com
}

check for

updates

Citation: Kıvanç Altunay, İ.; Mercan,

S.; Özkur, E. Tattoos in

Psychodermatology. Psych 2021, 3,

269-278. https://doi.org/10.3390/

psych3030021

Academic Editors: Jacek

C. Szepietowski and Mosad Zineldin

Received: 30 May 2021

Accepted: 2 July 2021

Published: 6 July 2021

Publisher's Note: MDPI stays neutral with regard to jurisdictional claims in published maps and institutional affiliations.

Copyright: (c) 2021 by the authors. Licensee MDPI, Basel, Switzerland. This article is an open access article distributed under the terms and conditions of the Creative Commons Attribution (CC BY) license (https:// creativecommons.org/licenses/by/ $4.0 /)$.

\begin{abstract}
Tattooing is a permanent form of body art applied onto the skin with a decorative ink, and it has been practiced from antiquity until today. The number of tattooed people is steadily increasing as tattoos have become popular all over the world, especially in Western countries. Tattoos display distinctive designs and images, from protective totems and tribal symbols to the names of loved or lost persons or strange figures, which are used as a means of self-expression. They are worn on the skin as a lifelong commitment, and everyone has their own reasons to become tattooed, whether they be simply esthetic or a proclamation of group identity. Tattoos are representations of one's feelings, unconscious conflicts, and inner life onto the skin. The skin plays a major role in this representation and is involved in different ways in this process. This article aims to review the historical and psychoanalytical aspects of tattoos, the reasons for and against tattooing, medical and dermatological implications of the practice, and emotional reflections from a psychodermatological perspective.
\end{abstract}

Keywords: tattoo; psychodermatology; body art; self-identity

\section{Introduction}

Tattooing is a body art in which some symbols, drawings, or lettering are imprinted onto the skin of an individual with a permanent dye or ink. These materials are injected into the skin by a tattooist or tattoo artist. Therefore, the process of tattooing involves three main constituents: the skin of the client, an image or design, and a tattooist. The skin of the client is a canvas, which functions as a painter's tool. Clients have many objectives, which usually include attracting others, beautifying themselves, identifying themselves as part of a specific group, obtaining a particular social status and fashion sense, and marking a significant event or statement. Thus, a client chooses whatever image or design they want and the tattooist is simply a performer (tattoo artist). These images on the skin may have very different meanings for individuals and reflect various desires, emotions, and states of mind to the outside world. In fact, the skin is the largest-and the only visible - organ of the human body, and it is readily noticed by others. Beyond its physiological functions, the skin is a source of self-esteem, contributes to self-image, and plays a significant role in the socializing process throughout an individual's life [1]. Thus, there is a relationship between the tattoos on one's skin and one's emotions, identity, and sociocultural environment. Finally, the location and importance of tattoos in terms of what they reveal about emotions and psychological states should be taken into consideration in dermatologic settings and medicine.

The word "tattoo" was derived from the Tahitian word "tatau" (to mark) and later entered the English language through James Cook's voyages. The history of tattoos can be traced back to 12,000 B.C. Thus, as with art on cave walls, drawing on and dying the skin are ancient practices as well [2]. Unfortunately, in contrast to art on cave walls, tattoos on bodies cannot continue their existence for so long. The only exception to this is tattoos found on frozen mummies. Ötzi, the Iceman, who was believed to have lived between 3370 and 3100 B.C., had numerous tattoos of simple dots and lines on various parts of his body 
that were made with carbon ink [3]. Ötzi's body was found in the Ötzal Alps, and hence he earned this nickname, "Ötzi". Egyptian mummies also had tattoos. In ancient Egypt, drawings of Hathor and the god Bes have been encountered, especially on women who were dancers or musicians [4]. Historical figures of tattoos consist of religious, sensuous, and patriotic themes, and are still common to this day [2]. From the ancient Middle East, the practice of tattooing has spread far and wide as a traditional religious and cultural phenomenon. Throughout history, it was banned by some emperors and religions, but the practice continued to exist and grew as a custom in Eastern and Western regions in the 18 th and 19th centuries. Its popularity waxed and waned during this period for different reasons, usually related to social conventions [5].

While tattoos have generally been a cultural taboo in modern Western societies and have been associated with certain marginalized or social groups, such as criminals and prostitutes, they are more acceptable, common, and popular today because of media practices [6,7]. The prevalence of tattoos in the general population has reached $10 \%$ to $30 \%$ in especially industrialized countries [8-10]. They have been more frequently encountered among younger people and men; however, gender discrepancies have lessened in some countries, such as the United States and Australia, and women are now more likely than men to have a tattoo $[6,11,12]$. Even though increasing numbers of people with tattoos are reported in modern societies, the practice still remains more prevalent within some particular social subgroups, such as soldiers, gang members, and criminals. Epidemiological studies conducted by Kruger indicate that military personnel, athletes, inmates, youth gangs, and drug users are part of a trend of having tattoos $[8,13]$. Undoubtedly, the higher prevalence of tattoos in some groups may be explained by certain factors, including peer influence, social status, collective roles, or identity. Nevertheless, there are some studies that can shed light on the underlying realities regarding psychological dynamics, personalities, self-identity, and character traits.

\section{Psychoanalytic Aspects and Getting under the Skin}

Creating symbols is an essential and primal human phenomenon, and the possibilities are diverse and endless. The use of symbols can be considered the most important method for adapting to reality. Sculpture, painting, and tattoo arts are the most frequently used tools for symbolizing and expressing experiences that people have difficulty contextualizing. The visual image almost always carries a symbolic meaning [14]. Symbolization also arises from intrapsychic conflicts.

Tattoos also reflect the developmental state of the ego and the way it deals with objects. The images chosen range from tiny, cute figures to spooky figures that cover almost the entire body.

From a psychoanalytic point of view, getting a tattoo may carry meanings relevant to symbiosis or separation in the mother-baby relationship, exhibitionism, expression of spiritual pain, or acquiring a feeling of wholeness by inflicting pain on the body.

In psychoanalytical terms, Freud's two papers on totems and taboos [15] and group psychology [16] are important to understand tattooing. In his group psychology paper, Freud stated that the psyche of the subject is intimately related to the dynamics of the group from the beginning. When human beings are gathered together, their individual ego is dissolved in the group. The subject feels themselves part of the "insuperable power" of the group and loses their personal responsibility and moral values. They may act on primitive drives, which may lead to violence, barbarism, and destructiveness or conversely to heroism. People may abandon their personal interests readily and sacrifice themselves for the sake of the group. Here it could be noted that the tattoo may signify a group allegiance. What it demands of its heroes is strength, or even violence. It wants to be ruled and oppressed and to fear its masters. Fundamentally, it is entirely conservative, and it has a deep aversion to all innovations and advances and has an unbounded respect for tradition. We can say that some tattoos are visual representations of the aims and goals that bring group members together. According to group dynamics, tattooing ensures 
that members belong to the group, and also helps group members bond with each other through strong feelings. The leader of the group loves each member of the group like a father and brings them together under his own system. A tattoo represents belonging to this organization.

Freud's book on totems and taboos begins with his curiosity about Australian aborigines in their tribes. He explored how primitive people established totemism and produced taboos instead of religious, social, and moral facts. These tribes are named after the animals they consider totems. Freud sees the totemism system as originating from the sons killing and eating the first father, in theory. The father complex observed in these sons-the fear of the power of the father and, on the other hand, the envy and desire to destroy him because he has all the women of the herd-led to the term the Oedipus complex. Prevalent feelings for the father, such as love and hatred, manifested themselves in the first human tribe in the act of killing him and eating his flesh. Then, the tribe transitioned to considering the totem animal sacred instead of the father. The totem animal was killed and eaten by all totem members in a feast held once a year, which Freud interpreted as a celebration of siblings being victorious over the father. Each clan has its own totem, which might be an animal or a plant, that is believed to be the common ancestor of the clan and a helper or guardian after death. Primitives established prohibitions to protect their clans, which were called taboos, and these included acts like incest and killing the totem animal, among others. The words "tattoo" and "taboo" come from the same Polynesian language, and "taboo", which comes from the term "tapu", is related to the Polynesian tattoo culture. People who gave tattoos were called "tapu", which means sacred and special. It could be theorized that tattoos got some of their importance from the need to distinguish each family, tribe, and clan from one another so that nobody could ever be mistaken about another's identity because of the permanent marks [14]. While tattoos were used to emphasize the sacred and forbidden in prehistoric clans, today they are used to symbolically express what is special, sacred, and hidden for the individual person.

Tattooing is about the body, and the skin in particular. As the concept of the ego has not developed in newborns yet, Freud mentions a bodily ego during infancy $[15,17]$. The skin is the main communication channel with the mother before language develops. It can be said that tattooing on the skin is also a nonverbal way of communication and expressing feelings, emotions or thoughts beyond words for an adult. The skin is like a transition area between the self and others. Tattoos on this barrier are related to both the object and subject. The deepest unconscious conflicts may be expressed by visual shapes and drawings on the skin via tattoos. A tattoo is a dialectic snapshot of the parental relationship, the desire of being close or far, or the desire to be like others or different from them via individualization or separation. People might seek to stop unconscious conflicts and create balance with tattoos [18]. When unconscious taboos impair psychical balance and equilibrium, intense feelings of fear of being abandoned or mingling with one's mother can occur. Tattooing provides a transitional object by both an actual penetration of the skin and the creation of a symbol. Winnicott mentioned these transitional objects as a defense against anxiety [19]. These transitional objects are one of the first steps in the process of separation-individualization. In our study, which was conducted to determine the cutaneous and psychopathological findings on patients with substance abuse, some patients had tattooed writings of their mother's names or "my dear mom" on their most visible skin areas [20]. Indeed, tattoos may be considered a kind of artificial reinforcement of the body boundary that helps strengthen one's sense of ego [2]. Furthermore, the fact that tattooing may have a compensatory experience for immature egos has also been hypothesized by Hamburger et al. [21].

Tattooing is a broader kind of secular and spiritual writing on the body through which the skin is used as prime material for self-expression [22]. In our research, we noticed that tattooing replaces self-cutting behavior in heroin addicts. We can say that tattooing is a stage between cutting and verbalizing one's unconscious conflicts or unexpressed feelings such as anger or sadness [20]. Tattooing might also be related to erotogenic masochism 
inherent in the body or represent a way of acting out repressed memories or feelings instead of verbalizing them [23]. Kohut's theory of narcissistic injury and fragmentation of the self with parental failure might also be related to tattoos [24]. In this case, tattoos might be used as self-objects to repair the fragmented self with trauma.

\section{Emotions and Motivations in Tattooed People}

Of note is that tattoos are visible versions of emotions. The skin is a mirror of one's feelings and serves to reflect one's inner world. Emotions and motives, which are closely related to each other, may be highly variable with respect to tattooing. Possession of the power of the object represented in a tattoo, obtaining a protective effect, desiring good fortune, or recovering from an illness may be motives for getting a tattoo. Tattoos can be a reflection of life cycles, losses of loved ones, desires about one's future, or fears. Sometimes, tattooing is a way to keep the memory of a person alive and to express an intense feeling in a more tangible way. However, one of the most encountered motives is self-identity or individualization. In particular, adolescents and young adults are prone to get tattoos for this purpose [25-27] because this stage of the human life cycle is subject to identity crisis, as suggested by Ericsson [27]. Martin [28] suggested that tattoos may play a role in identity formation in teenagers but may not characterize the personalities or self-perceptions of those with and without tattoos. He highlighted that adolescents' bodily decorations can often be self-constructive and adorning efforts instead of mutilatory and destructive acts. Tiggemann and Hopkins [29] demonstrated that tattooing is a means to achieve self-distinctiveness and represents a bodily expression of uniqueness. A tattoo can also be seen as a mediator to draw attention and thus highlight self-identity [30]. There are, per se, numerous data to support this idea. Tattoos and body piercings should be interpreted as a symbol of the desire to show a subject's identity rather than as a marker of psychopathology, according to the results of a study carried out by Preti et al. [31]. Along similar lines, Dickson et al. stated that tattoos serve a symbolic meaning-making function that is part of the development of adult identity [32]. According to Dickson et al., body decoration is another strong motive for having tattoos. Women are more likely to have tattoos for body decoration, while men are more likely to have an image or symbol representing group identity [2]. One recent study revealed that women with tattoos tend to perceive the ideal body image as being a tattooed body [33]. Another investigation reported that female footballers prefer smaller and also more discreet tattoos for the purpose of ornamentation, while male footballers choose extensive tattoos, possibly to enhance their domination. Moreover, extroverted, risk-taking, aggressive, and outgoing players with tattoos were shown to be more successful in forward positions than those in defensive positions [34]. Nevertheless, in both men and women, tattooing accentuates their own sexual perceptions about sexual attractiveness and potency [33,35]. Women were reported to be more sexually active if they had tattoos, and a certain number of tattoos was associated with the number of premarital sexual partners and age at first intercourse both in men and women [36]. Additionally, there is an association between tattoos and risky sexual behaviors or a history of sexual abuse [37].

There are, undoubtedly, other motives for getting tattooed. Some people may be inclined to be addicted to tattoos [37]. In fact, more than $50 \%$ of the participants admitted a tendency toward addiction, and even an obsession concerning tattoos, according to a study conducted by Stirn et al. [38]. For some, tattoos are an art. Some people allow themselves to get tattooed simply because it is beautiful. Some "collect" this art and choose to be tattooed by various artists to amass a collection of tattoos on their body, while for others, a tattoo is simply attained for the sake of fashion [39]. A survey from Greece demonstrated that $77 \%$ of all subjects had motives of ideology/message and fashion/esthetic [40]. Likewise, it was noted that personal and esthetic preferences were strong motivators, especially for transmasculine persons in a study [41].

Although not so frequent, medical applications also exist. For instance, tattoos for areolar reconstruction in burn victims and breast cancer can be used to conceal scars or 
disfigurations originating from breast reconstructions and thus to accelerate emotional healing [42,43]. Another medical purpose for tattoos is use in radiation therapy, especially for breast cancer. For decades, tattoos and temporary skin marks have been used in the delivery of radiation therapy, and tattoos help radiation therapists effectively and accurately position patients [44]. The use of permanent tattoos can be a concern for some patients and may have an impact on body image. Tattoos and temporary marks provide a visible and constant reminder of the disease and the patient's treatment and fight against it.

Additionally, tattoos can potentially be life-saving tools that call attention to underlying medical conditions, such as diabetes and allergies, among others. They may also have positive effects beyond providing medical alerts, in that they represent a coping strategy and active mastery of chronic diseases [45]. DNR tattoos (do not resuscitate) fall into this category as well. These kinds of tattoos have legal and ethical repercussions when emergency personnel need to resuscitate a patient [46].

Accidental tattoos are caused by persistent depositing of exogenous pigment particles, such as metal salts or carbon, in the dermal or subcutaneous layers of the skin due to traumas, iatrogenic causes, and chronic intake of some drugs [47]. These tattoos can be reminders of past events and can remain anywhere unintentionally. Hence, they can produce negative emotions.

\section{Personality Traits and Psychopathologies}

The relationship between tattoos, personality traits, and mental illness has been frequently investigated. Tattooing has been empirically associated with personality disorders and psychopathic personality [48-52]. In fact, some researchers have highlighted that the presence of a tattoo on physical examination may indicate the possibility of an underlying psychiatric condition [53]. Previous investigations involving inmates in particular revealed that personality types more likely to engage in tattooing include antisocial, sadistic, negativistic, and borderline traits [51]. Tattooed adults were found to have significantly higher reactive rebelliousness, anger, and verbal aggression than non-tattooed adults in one study [53]. Another study found higher scores on the evaluation of extraversion and experience seeking [54]. However, these results were assessed by the authors as non-significant due to small effect sizes. In contrast, Lamberg pointed out that possessing a tattoo or body piercing is strongly associated with the likelihood of aggression, impulsivity, and drug use [55]. In line with this, the content of the tattoos in our study, including graphic symbols of death and immoral characters, was evaluated as expressing feelings of aggression that come together with the desire to destroy oneself, problems with interpersonal relations, and psychotic thoughts [20]. The participants of our study were illicit drug users. Ceylan et al. [56] conducted a survey with adolescent prisoners and found that conduct disorder $(85.5 \%)$, attention deficit hyperactivity disorder $(61.8 \%)$, depression $(50 \%)$, substance abuse $(40.8 \%)$, post-traumatic stress disorder $(19.7 \%)$, and psychotic disorder $(3.9 \%)$ were more frequent among these subjects as well as a higher tattooing frequency $(65.8 \%)$ than the control group. Needless to say, these results cannot be attributed to the general population. However, recent investigations and general population surveys continue to report that individuals with tattoos are more likely to engage in risky behaviors, such as smoking, drug use, and having a number of sexual partners, than their non-tattooed counterparts. In 2017, the American Academy of Pediatrics released its first clinical report on tattoos among adolescents and young adults, noting that tattoos may co-occur with high-risk behaviors [57]. In a nationally representative sample of German residents, those with tattoos reported feeling significantly worse in terms of mental health than the non-tattooed respondents [58]. These data indicate that despite the cultural and sociological shifts in the modern era in which tattoos are considered more acceptable and are more prevalent, the possibility of comorbid mental health issues persists. In a 2016 study, Swami et al. [59] pointed out that it appears that tattoos are now mainstream and that any previous demographic or socioeconomic boundaries have been flattened. They also found that tattooed adults had higher motor impulsivity and were more willing to take recreational and health 
and safety risks. However, the effect sizes of these differences were small to negligible. They concluded that the mainstreaming of body art now means that tattooed and nontattooed adults are more similar than different. Overall, these mixed results indicate a clear need for further investigation.

Recreational drug use or substance abuse has been a striking issue associated with people with tattoos. Pirrone et al. [60] claimed that tattooing has the function of reinforcing beliefs about how to perceive oneself, and this is especially common among drug addicts, in whom the presence of tattoos reinforces the illusory belief of self-esteem and an internal locus of control, according to the results of their study. Laumann et al. suggested that tattooed people are more likely to use recreational drugs compared to non-tattooed individuals [61]. In our study, it was observed that those who used heroin had more tattoos than those who used bonsai, and that patients who had tattoos started earlier on with regular substance use. Depression, somatization, interpersonal sensitivity, anxiety, psychosis, and tattoos were found to be statistically higher in patients using heroin than in bonsai patients. It can be said that patients who use heroin struggle to symbolize and express their feelings. As a result, they may resort to tattooing to cope with depression and other psychiatric problems [20]. Descriptive data show that drug users with tattoos prefer larger tattoos, begin tattooing at a very young age, and possess more tattoos than adults who do not use drugs [60]. Tattooing was also found to be associated with violence, weekly alcohol consumption, illicit drug use, and dropping out of school in a Taiwanese study [62]. In North America in particular, tattooing is associated with risk-taking behaviors, including using cannabis and alcohol.

The association between possessing tattoos and engaging in self-injurious behaviors and suicide has also been investigated based on the fact that risk-taking behaviors, such as illicit drug use, sexual disinhibition, gang affiliations, and so on, are more common in individuals with tattoos than in those without tattoos. However, there are some conflicting results on this point. While some research proposes that teens and young adults with tattoos are at increased risk of suicide attempts and unhealthy practices, some claim that tattoos could be a protective or mitigating factor for suicidal ideation and attempts $[63,64]$. One study in particular noted that expletive tattoos in a forensic context may be associated with unnatural and violent deaths, and that the study of certain subgroups of tattooed individuals may be useful in discerning specific trends that are unclear if "tattoos" are treated as a homogeneous phenomenon [65].

\section{Dermatological Implications of Tattoos: Psychodermatologic Results}

\subsection{Tattoo Regret}

While there has been an exponential increase in decorative tattooing as a body art in teenagers and young adults, there has also been a similar increase in patients seeking removal of tattoos for various psychosocial reasons, especially when names are tattooed, and patients have a change of heart or faith [66]. Dermatologists are an important part of this process, which is known as tattoo regret or a desire for tattoo removal. Undoubtedly, the development of new laser systems in dermatology has provided an advantage in these removal procedures. People easily get tattoos, but they can now also get rid of them, although tattoo removal may be a challenge in medical settings due to some complications and incomplete removal. Tattoo removal is uncertain despite advances in laser technology and may result in undesired cosmetic outcomes $[58-60,67,68]$. These outcomes may give rise to psychological issues along with other complications of the removal procedure due to dissatisfaction with the results [58,59]. Different studies report growing numbers of people with tattoo regret, reaching at least half of individuals with tattoos in some studies [69-71].

The reasons behind this regret may be variable. A United Kingdom study showed that men are more likely to regret their tattoos and are three times more likely to regret them if they were acquired under the age of 16 years [71]. Current fashions and changing societal attitudes toward tattoos, as well as an improved self-esteem and intention to appear more professional and mature, may be additional causes for regret. Moreover, tattoos acquired at 
younger ages may become a source of later embarrassment, which often arises by 40 years of age [72]. At the same time, some negative perceptions about tattooed individuals by others can lead to social stigmatization and increased interest in laser removal centers. These people can be marginalized or not be approved in some work or social settings because of prejudices or images of tattoos [73,74]. Professional settings, personal factors such as age or gender, and tattoo features including size, location, and content can affect social disapproval [6]. In contrast to the aforementioned positive motivations, including identity representation, attractiveness, and beauty, social stigma due to tattoos precipitates an avoiding effect.

Dermatological complications could arise from a tattoo itself or from tattoo removal procedures. In particular, delayed complications can occur and they are also primary reasons for tattoo removal, such as pigmentary changes, hypopigmentation and hyperpigmentation, paradoxical darkening of cosmetic tattoos and allergic reactions, the presence of residual pigmentation or ghost images, scarring and textural changes, lichenoidgranulomatous-papulonodular reactions, and flares of existing dermatologic illness such as scar sarcoidosis, discoid lupus, cutaneous vasculitis, and pyoderma gangrenosum [66,68]. Additionally, tattoo inks are sometimes compounded from large numbers of chemicals, none of which is approved for injection into humans by the FDA (US Food and Drug Administration); these inks frequently include known carcinogens [73]. Although it is rare and neglected in the medical literature, MRI-induced tattoo complications, including first or second-degree burns or tingling and tightening and stinging pain, can occur with tattoos with iron oxide [75]. Concerning complications of tattoo removal processes, particularly conventional non-laser methods, can result in chronic scarring, redness, and itching and dyspigmentation. This is another scenario in which victims seek additional medical, surgical, and psychological treatments [76].

\subsection{Dichotomy of Medical Complications and Psychological Healing}

Although complications due to tattoo practices may be a serious health problem, tattoos are also used for medical purposes to camouflage unwanted scars or wound marks and thus allow patients to overcome some negative psychosocial experiences due to burns, postsurgical/postmastectomy scarring, self-harm scars, accidents, and so on [77]. Indeed, scars, especially on visible areas, are disfiguring and stigmatizing with resultant psychosocial implications encompassing anxiety, depression, low self-esteem, avoidance from social activities, and impaired quality of life. As a result, tattooing has a healing and transforming effect that can lead to strengthening one's self-image, regaining control, and reclaiming the body after traumatic experiences [78]. Likewise, some people who have chronic and disfiguring cutaneous disorders, namely psoriasis, vitiligo, and hidradenitis suppurativa, may be eager to get tattoos and other body modifications for the betterment of their body image [79]. While a dermatologic disease can lead to stigmatization and have a negative psychological impact, tattoos can help overcome that impact through their decorative effect. However, in some cultures stigma surrounding tattoos may remain because tattoos were historically associated with criminality and deviant behavior [80]. This dichotomy remains to be considered.

\section{Conclusions}

Tattooing as a body-skin art and as a means of personal expression is a multifaceted phenomenon associated with cultural, social, psychological, and medical aspects. Tattooing has been around for ages and seems to be increasing in popularity with accelerated momentum. Every person has his or her own reasons to obtain a tattoo. From a psychological point of view, these reasons are complex. Tattooing, whether with individual motives or medical purposes, obviously bolsters the development of one's identity and self-esteem and has positive effects on one's body image through the skin. However, dermatological complications, general health risks and the possibility of regret should not be overlooked. 


\begin{abstract}
Author Contributions: Conceptualization, İ.K.A.; methodology, S.M.; software, E.Ö.; validation, İ.K.A.; formal analysis, E.Ö.; investigation, S.M.; resources, I.K.A.; data curation, S.M.; writingoriginal draft preparation, İ.K.A., S.M.; writing-review and editing, E.Ö.; visualization, S.M.; supervision, İ.K.A.; project administration, İ.K.A.; funding acquisition, Nil. All authors have read and agreed to the published version of the manuscript.
\end{abstract}

Funding: This research received no external funding.

Institutional Review Board Statement: Not applicable.

Informed Consent Statement: Not applicable.

Conflicts of Interest: The authors declare no conflict of interest.

\title{
References
}

1. Mercan, S.; Kivanç Altunay, I.P. A collaboration between psychiatry and dermatology [article in Turkish]. Turk Psikiyatr. Derg. 2006, 17, 305-313.

2. Grumet, G.W. Psychodynamic implications of tattoos. Am. J. Orthopsychiatry 1983, 53, 482-492. [CrossRef] [PubMed]

3. Gilbert, S. Tattoo History: A Source Book: An Anthology of Historical Records of Tattooing throughout the World; Powerhouse Books: New York, NY, USA, 2000.

4. Rubin, A. Marks of Civilization; Museum of Cultural History: Los Angeles, CA, USA, 1988.

5. Levy, J.; Sewell, M.; Goldstein, N., II. A short history of tattooing. Dermatol. Surg. 1979, 5, 851-856. [CrossRef] [PubMed]

6. Roggenkamp, H.; Nicholls, A.; Pierre, J.M. Tattoos as a window to the psyche: How talking about skin art can inform psychiatric practice. World J. Psychiatry 2017, 7, 148. [CrossRef] [PubMed]

7. Kertzman, S.; Kagan, A.; Hegedish, O.; Lapidus, R.; Weizman, A. Do young women with tattoos have lower self-esteem and body image than their peers without tattoos? A non-verbal repertory grid technique approach. PLoS ONE 2019, 14, e0206411. [CrossRef]

8. Kluger, N. Epidemiology of tattoos in industrialized countries. Tattooed Skin Health 2015, 48, 6-20.

9. Kluger, N. Insights into worldwide interest in tattoos using google trends. Dermatology 2019, 235, 240-242. [CrossRef]

10. Mueller, S.M.; Bayer, M.; Gysin, S. Role of tattoos in football: Behavioral patterns and success-Analysis of the FIFA World Cup 2018. Clin. Dermatol. 2020, 38, 788-792. [CrossRef] [PubMed]

11. King, K.A.; Vidourek, R.A. Getting inked: Tattoo and risky behavioral involvement among university students. Soc. Sci. J. 2013, 50, 540-546. [CrossRef]

12. Mortensen, K.; French, M.T.; Timming, A.R. Are tattoos associated with negative health-related outcomes and risky behaviors? Int. J. Dermatol. 2019, 58, 816-824. [CrossRef]

13. Atkinson, M. Tattooing and civilizing processes: Body modification as self-control. Can. Rev. Sociol. Rev. Can. Sociol. 2004, 41, 125-146. [CrossRef] [PubMed]

14. Langfeld, H.S. Concerning the image. Psychol. Rev. 1916, 23, 180. [CrossRef]

15. Freud, S. Totem e tabù: Alcune concordanze nella vita psichica dei selvaggi e dei nevrotici (1912-1913). Opere 1980, 7, 3-164.

16. Freud, S. Group psychology and the analysis of the ego (translated by J. Strachey). In The Standard Edition of the Complete Psychological Works of Sigmund Freud; The Hogarth Press: London, UK, 1921; Volume 18, pp. 1920-1922.

17. Freud, S. Neurosis and psychosis. In The Standard Edition of the Complete Psychological Works of Sigmund Freud: The Ego and the Id and Other Works; The Hogarth Press: London, UK, 1961; Volume XIX, pp. 147-154.

18. Karacaoglan, U. Tattoo and taboo: On the meaning of tattoos in the analytic process. Int. J. Psychoanal. 2012, 93, 5-28. [CrossRef] [PubMed]

19. Winnicott, D.W. 10 Transitional objects and transitional phenomena: A study of the first not-me. In Essential Papers on Object Relations; New York University Press: New York, NY, USA, 1986; Volume 254.

20. Can, Y.; Altunay, I.K.; Mercan, S.; Evren, C.; Pospos, O.H.; Ozkur, E. Dermatological and psychiatric manifestations in heroin and bonsai use disorder. Heroin Addict. Relat. Clin. Probl. 2020, 22, 5-14.

21. Hamburger, E. Tattooing as a psychic defence mechanism. Int. J. Soc. Psychiatry 1966, 12, 60-62. [CrossRef]

22. Hewitt, K. Mutilating the Body: Identity in Blood and Ink; Popular Press: Madison, WI, USA, 1997.

23. Freud, S. The economic problem of masochism. In The Standard Edition of the Complete Psychological Works of Sigmund Freud, Volume XIX (1923-1925): The Ego and the Id and Other Works; Hogarth Press: London, UK, 1961; pp. 155-170.

24. Kohut, H.; Wolf, E.S. The disorders of the self and their treatment: An outline. Int. J. Psycho Anal. 1978, 59, 413-425.

25. Armstrong, M.; McConnell, C. Promoting informed decision-making about tattooing for adolescents. J. Sch. Nurs. Off. Publ. Natl. Assoc. Sch. Nurses 1994, 10, 27-28.

26. Armstrong, M.L.; McConnell, C. Tattooing in adolescents: More common than you think-the phenomenon and risks. J. Sch. Nurs. Off. Publ. Natl. Assoc. Sch. Nurses 1994, 10, 26-33.

27. Erikson, E.H. Identity: Youth and Crisis; WW Norton \& Company: New York, NY, USA, 1968.

28. Martin, A. On teenagers and tattoos. J. Am. Acad. Child Adolesc. Psychiatry 1997, 36, 860-861. [CrossRef] [PubMed] 
29. Tiggemann, M.; Hopkins, L.A. Tattoos and piercings: Bodily expressions of uniqueness? Body Image 2011, 8, 245-250. [CrossRef] [PubMed]

30. Swami, V. Marked for life? A prospective study of tattoos on appearance anxiety and dissatisfaction, perceptions of uniqueness, and self-esteem. Body Image 2011, 8, 237-244. [CrossRef] [PubMed]

31. Preti, A.; Pinna, C.; Nocco, S.; Mulliri, E.; Pilia, S.; Petretto, D.R.; Masala, C. Body of evidence: Tattoos, body piercing, and eating disorder symptoms among adolescents. J. Psychosom. Res. 2006, 61, 561-566. [CrossRef] [PubMed]

32. Dickson, L.; Dukes, R.L.; Smith, H.; Strapko, N. To ink or not to ink: The meaning of tattoos among college students. Coll. Stud. J. 2015, 49, 106-120.

33. Taylor, P.J.; Usher, S.; Jomar, K.; Forrester, R. Investigating self-concept in self-harm: A repertory grid study. Psychol. Psychother. Theory Res. Pract. 2021, 94, 171-187. [CrossRef]

34. Kluger, N.; Ahava, R. Tattoos among professional football players in the 2018-2019 Spanish La Liga season. Ann. Dermatol. Venereol. 2021, 148, 112-115. [CrossRef] [PubMed]

35. Antoszewski, B.; Sitek, A.; Fijałkowska, M.; Kasielska, A.; Kruk-Jeromin, J. Tattooing and body piercing-what motivates you to do it? Int. J. Soc. Psychiatry 2010, 56, 471-479. [CrossRef] [PubMed]

36. Nowosielski, K.; Kurpisz, J.; Kowalczyk, R. Sexual inhibition and sexual excitation in a sample of Polish women. PLoS ONE 2021, 16, e0249560. [CrossRef] [PubMed]

37. Kluger, N. Tattooed people, who are you? Demographic and behavioral characteristics of tattooed individuals. Ann. Dermatol. Venereol. 2015, 142, 410-420. [CrossRef] [PubMed]

38. Stirn, A.; Oddo, S.; Peregrinova, L.; Philipp, S.; Hinz, A. Motivations for body piercings and tattoos-The role of sexual abuse and the frequency of body modifications. Psychiatry Res. 2011, 190, 359-363. [CrossRef] [PubMed]

39. Kierstein, L.; Kjelskau, K.C. Tattoo as art, the drivers behind the fascination and the decision to become tattooed. In Tattooed Skin and Health; Karger Publishers: Basel, Switzerland, 2015; Volume 48, pp. 37-40.

40. Notara, V.; Gnardellis, C.; Sakellari, E.; Soultatou, P.; Petratou, E.; Dragomanovits, K.; Lagiou, A. Health knowledge and motives on tattooing: A community-based cross-sectional study in Greece. J. Cosmet. Dermatol. 2021. [CrossRef] [PubMed]

41. Ragmanauskaite, L.; Kim, J.; Zhang, Q.; Luk, K.M.; Getahun, D.; Silverberg, M.J.; Goodman, M.; Yeung, H. Self-reported tattoo prevalence and motivations in transgender adults: A cross-sectional survey. Dermatol. Online J. 2020, 26. [CrossRef]

42. Osborn, L.P.; Cohen, P.R. Emotional healing with unconventional breast tattoos: The role of temporary tattoos in the recovery process after breast carcinoma and mastectomy. Clin. Dermatol. 2018, 36, 426-429. [CrossRef] [PubMed]

43. Farhadi, J.; Maksvytyte, G.K.; Schaefer, D.J.; Pierer, G.; Scheufler, O. Reconstruction of the nipple-areola complex: An update. J. Plast. Reconstr. Aesthetic Surg. 2006, 59, 40-53. [CrossRef] [PubMed]

44. Probst, H.; Dodwell, D.; Gray, J.; Holmes, M. An evaluation of the accuracy of semi-permanent skin marks for breast cancer irradiation. Radiography 2006, 12, 186-188. [CrossRef]

45. Kluger, N.; Saleh Aldasouqi, M. The motivations and benefits of medical alert tattoos in patients with diabetes. Endocr. Pract. 2013, 19, 373. [CrossRef] [PubMed]

46. Kluger, N.; Aldasouqi, S. Medical alert tattoos in minors should not be advocated. Eur. J. Pediatrics 2013, 172, 1141. [CrossRef] [PubMed]

47. Eggenschwiler, C.D.; Dummer, R.; Imhof, L. Laser Treatment of Accidental Tattoos: Experience at a Tertiary Referral Center. Dermatology 2020, 236, 383-389. [CrossRef] [PubMed]

48. Measey, L.G. The psychiatric and social relevance of tattoos in Royal Navy detainees. Br. J. Criminol. 1972, 12, 182-186. [CrossRef]

49. Armstrong, M.L. Career-oriented women with tattoos. Image J. Nurs. Scholarsh. 1991, 23, 215-220. [CrossRef]

50. Schunter, M.; Holzki, G. Tattooing and self-mutilation of the skin in neurotic character disorder. Der Hautarzt Z. fur Dermatol. Venerol. Verwandte Geb. 1990, 41, 305-308.

51. Manuel, L.; Retzlaff, P.D. Psychopathology and tattooing among prisoners. Int. J. Offender Ther. Comp. Criminol. 2002, 46, 522-531. [CrossRef] [PubMed]

52. McKerracher, D.W.; Watson, R. Tattoo marks and behaviour disorder. Brit. J. Criminol. 1969, 9, 167. [CrossRef]

53. Raspa, R.F.; Cusack, J. Psychiatric implications of tattoos. Am. Fam. Physician 1990, 41, 1481-1486. [PubMed]

54. Swami, V.; Pietschnig, J.; Bertl, B.; Nader, I.W.; Stieger, S.; Voracek, M. Personality differences between tattooed and non-tattooed individuals. Psychol. Rep. 2012, 111, 97-106. [CrossRef] [PubMed]

55. Lamberg, L. Prediction of violence both art and science. JAMA 1996, 275, 1712. [PubMed]

56. Ceylan, M.F.; Hesapcioglu, S.T.; Kasak, M.; Yavas, C.P. High prevalence of nonsuicidal self-injury, tattoos, and psychiatric comorbidity among male adolescent prisoners and their sociodemographic characteristics. Asian J. Psychiatry 2019, 43, 45-49. [CrossRef] [PubMed]

57. Breuner, C.C.; Levine, D.A. Adolescent and young adult tattooing, piercing, and scarification. Pediatrics 2017, 140 , e20163494. [CrossRef] [PubMed]

58. Stirn, A.; Hinz, A.; Brähler, E. Prevalence of tattooing and body piercing in Germany and perception of health, mental disorders, and sensation seeking among tattooed and body-pierced individuals. J. Psychosom. Res. 2006, 60, 531-534. [CrossRef]

59. Swami, V.; Tran, U.S.; Kuhlmann, T.; Stieger, S.; Gaughan, H.; Voracek, M. More similar than different: Tattooed adults are only slightly more impulsive and willing to take risks than non-tattooed adults. Personal. Individ. Differ. 2016, 88, 40-44. [CrossRef] 
60. Pirrone, C.; Castellano, S.; Platania, G.A.; Ruggieri, S.; Caponnetto, P. Comparing the emerging psychological meaning of tattoos in drug-addicted and not drug-addicted adults: A look inside health risks. Health Psychol. Res. 2020, 8, 9268. [CrossRef] [PubMed]

61. Laumann, A.E.; Derick, A.J. Tattoos and body piercings in the United States: A national data set. J. Am. Acad. Dermatol. 2006, 55, 413-421. [CrossRef] [PubMed]

62. Yen, C.-F.; Hsiao, R.C.; Yen, J.-Y.; Yeh, Y.-C.; Wang, P.-W.; Lin, H.-C.; Ko, C.-H. Tattooing among high school students in southern Taiwan: The prevalence, correlates and associations with risk-taking behaviors and depression. Kaohsiung J. Med Sci. 2012, 28, 383-389. [CrossRef] [PubMed]

63. Solís-Bravo, M.A.; Flores-Rodríguez, Y.; Tapia-Guillen, L.G.; Gatica-Hernández, A.; Guzmán-Reséndiz, M.; Salinas-Torres, L.A.; Vargas-Rizo, T.L.; Albores-Gallo, L. Are Tattoos an Indicator of Severity of Non-Suicidal Self-Injury Behavior in Adolescents? Psychiatry Investig. 2019, 16, 504. [CrossRef] [PubMed]

64. Stirn, A.; Hinz, A. Tattoos, body piercings, and self-injury: Is there a connection? Investigations on a core group of participants practicing body modification. Psychother. Res. 2008, 18, 326-333. [CrossRef] [PubMed]

65. Byard, R.W. Manner of death in individuals with expletive tattoos. J. Forensic Leg. Med. 2020, 71, 101931. [CrossRef] [PubMed]

66. Khunger, N.; Molpariya, A.; Khunger, A. Complications of tattoos and tattoo removal: Stop and think before you ink. J. Cutan. Aesthetic Surg. 2015, 8, 30. [CrossRef] [PubMed]

67. McIlwee, B.E.; Alster, T.S. Treatment of Cosmetic Tattoos: A Review and Case Analysis. Dermatol. Surg. Off. Publ. Am. Soc. Dermatol. Surg. 2018, 44, 1565-1570. [CrossRef] [PubMed]

68. Serup, J.; Bäumler, W. Diagnosis and therapy of tattoo complications. Curr. Probl. Dermatol. 2017, 52, $132-138$.

69. Shannon-Missal, L. Tattoo Takeover: Three in Ten Americans Have Tattoos, and Most Don't Stop at Just One. Harris Poll 2016, 12. Available online: https: / theharrispoll.com/tattoos-can-take-any-number-of-forms-from-animals-to-quotes-to-cryptic-symbolsand-appear-in-all-sorts-of-spots-on-our-bodies-some-visible-in-everyday-life-others-not-so-much-but-one-thi/ (accessed on 6 July 2021).

70. Kluger, N.; Misery, L.; Seite, S.; Taieb, C. Regrets after tattooing and tattoo removal in the general population of France. J. Eur. Acad. Dermatol. Venereol. 2019, 33, e157-e159. [CrossRef] [PubMed]

71. Aslam, A.; Owen, C. Fashions change but tattoos are forever: Time to regret. Br. J. Dermatol. 2013, 169, 1364-1366. [CrossRef] [PubMed]

72. Burris, K.; Kim, K. Tattoo removal. Clin. Dermatol. 2007, 25, 388-392. [CrossRef] [PubMed]

73. Kremer, P.; Pinedo, M.; Ferraiolo, N.; Vargas-Ojeda, A.C.; Burgos, J.L.; Ojeda, V.D. Tattoo removal as a resettlement service to reduce incarceration among Mexican migrants. J. Immigr. Minority Health 2020, 22, 110-119. [CrossRef] [PubMed]

74. Burgess, M.; Clark, L. Do the "savage origins" of tattoos cast a prejudicial shadow on contemporary tattooed individuals? J. Appl. Soc. Psychol. 2010, 40, 746-764. [CrossRef]

75. Alsing, K.K.; Johannesen, H.H.; Hansen, R.H.; Serup, J. Tattoo complications and magnetic resonance imaging: A comprehensive review of the literature. Acta Radiol. 2020, 61, 1695-1700. [CrossRef] [PubMed]

76. Hutton Carlsen, K.; Serup, J. Sequels to tattoo removal by caustic products. Skin Res. Technol. 2018, 24, 636-641. [CrossRef]

77. Yeates, R.; Rospigliosi, E.; Thompson, A.R. A mixed methods evaluation of medical tattooing for people who have experienced a burn injury. Scars Burn. Health 2018, 4, 2059513118784721. [CrossRef] [PubMed]

78. Reid-de Jong, V.; Bruce, A. Mastectomy tattoos: An emerging alternative for reclaiming self. Nurs. Forum 2020, 695-702. [CrossRef] [PubMed]

79. Guillem, P.; Raynal, H.; Wendling, A.; Kluger, N. Hidradenitis Suppurativa Influences Tattooing Practice in Women. Dermatology 2020, 236, 445-451. [CrossRef]

80. Broussard, K.A.; Harton, H.C. Tattoo or taboo? Tattoo stigma and negative attitudes toward tattooed individuals. J. Soc. Psychol. 2018, 158, 521-540. [CrossRef] [PubMed] 